\title{
Association between preoperative anaemia, blood transfusion rates and worse outcomes after major hepatobiliary surgery
}

\author{
Wilkinson $\mathrm{J}^{1}$, Baird $\mathrm{A}^{2}$, McCone $\mathrm{E}^{1}$, Snowden $\mathrm{C}^{1}$, Prentis $\mathrm{J}^{1}$ \\ 1. Dept of perioperative and critical care medicine \\ 2. Dept of Haematology \\ Newcastle upon Tyne NHS Trust, Newcastle, UK
}

\section{Background}

There is increasing evidence that anaemia is associated with worsen outcomes, increased rates of blood transfusion and ultimately increased cost peri-operatively. This has lead to an increased drive to treat anaemia pre-operatively, in order to optimise patients prior to surgery. Traditionally, cut of values derived from the WHO classification of anaemia have been used to guide treatment, however whether these values are appropriate in the peri-operative setting, and throughout different surgical modalities, remains to be investigated.

\section{Methods}

This is a retrospective review of 377 patient's undergoing major hepatobiliary surgery at a single centre between May 2015 and August 2017. Data was systematically collected from a prospectively held database.

Various factors were examined including: preoperative $\mathrm{Hb}$, transfusion rates, duration of surgery, and both critical care (all patients returned to ICCU post-op) and total hospital stay. The primary outcomes were to examine whether transfusion was associated with prolonged hospital stay and whether preoperative $\mathrm{Hb}$ is associated with increased transfusion rates.

\begin{tabular}{cccc}
\hline & $\mathbf{H b}<\mathbf{1 2 5}$ & $\mathbf{H b}<\mathbf{1 2 5}$ & $\mathbf{P}=$ \\
\hline $\mathbf{N}$ & 121 & 256 & \\
\hline Transfusion Rates & $46.2 \%$ & $10.9 \%$ & $<0.001$ \\
\hline ICCU Stay (Days) & $5.8(10.9)$ & $3.0(5.7)$ & 0.001 \\
\hline Hospital Stay (Days) & $24.5(27.9)$ & $16.9(16.6)$ & 0.002 \\
\hline
\end{tabular}

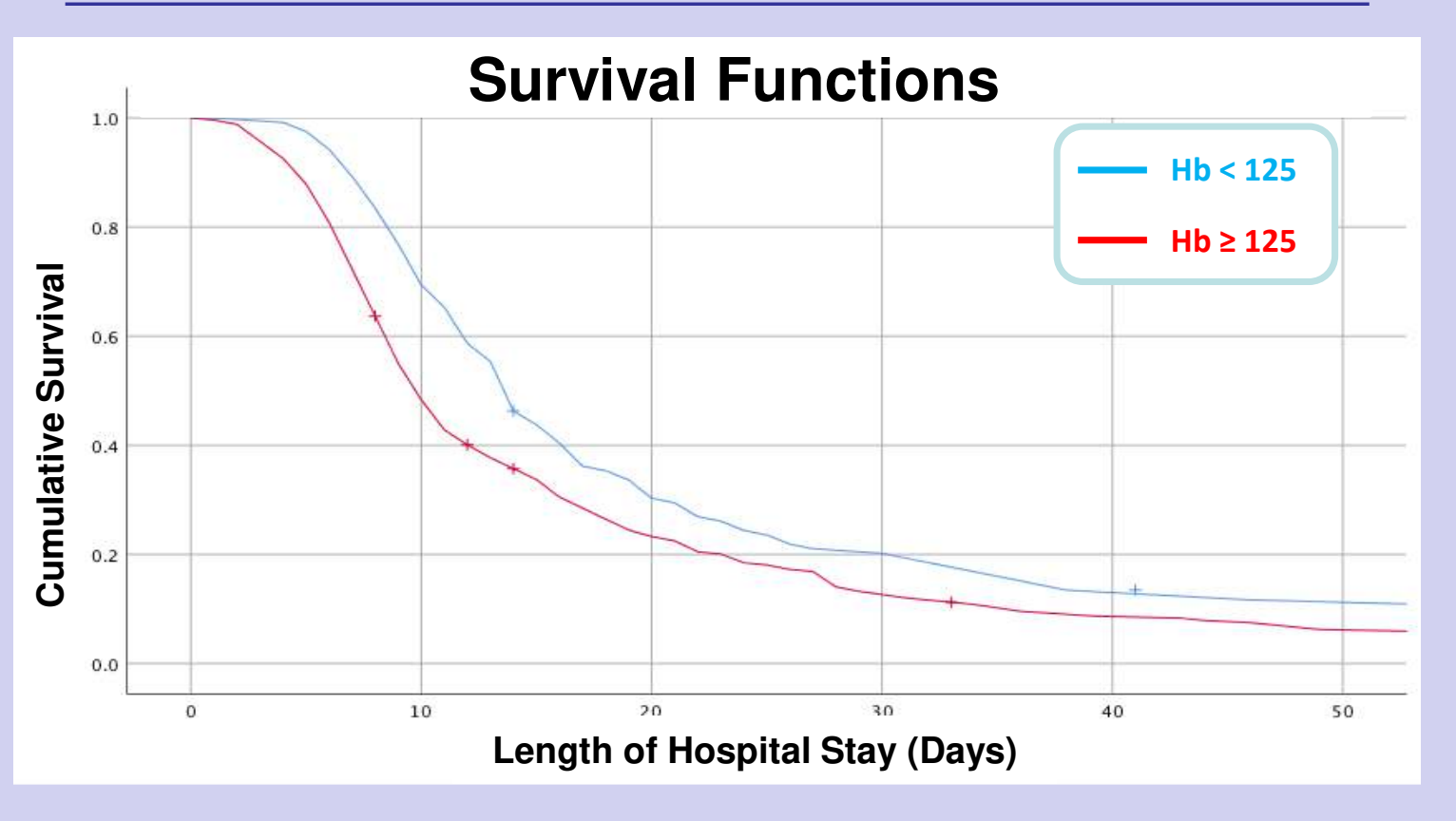

\begin{tabular}{ccccc}
\hline & $\begin{array}{c}\text { Not } \\
\text { Transfused }\end{array}$ & Transfused & $\mathbf{P}=$ \\
\hline $\mathbf{N}$ & 293 & 84 & \\
\hline Age & $64.1(11.5)$ & $63.3(11.2)$ & 0.55 \\
Sex & $182 \mathrm{M} \quad 111 \mathrm{~F}$ & $48 \mathrm{M} \quad 35 \mathrm{~F}$ & \\
\hline $\begin{array}{c}\text { Pre-op Hb } \\
\text { Length of Surgery } \\
\text { (Minutes) }\end{array}$ & $134(14.5)$ & $119(19.7)$ & $<0.001$ \\
\hline $\begin{array}{c}\text { ICCU Stay } \\
\text { (Days) }\end{array}$ & $1.93(2.0)$ & $10.2(14.5)$ & $<0.001$ \\
\hline $\begin{array}{c}\text { Total Hospital Stay } \\
\text { (Days) }\end{array}$ & $14.2(12.1)$ & $35.1(34.1)$ & $<0.001$ \\
\hline
\end{tabular}

\section{Results}

We had complete data recorded for all 377 patients. The perioperative blood transfusion rate was $22.3 \%$. Unsurprisingly, blood transfusion was associated with increased duration of surgery suggesting it was of a more complex nature. Both critical care and hospital length of stay were dramatically increased. The in-hospital mortality rate was $1.9 \%$. Of those that died all had received a blood transfusion.

Preoperative $\mathrm{Hb}$ levels were significantly reduced in those requiring a preoperative blood transfusion. ROC curve analysis revealed the optimum preop $\mathrm{Hb}$ to predict those at risk of blood transfusion was 125 (AUROC $=0.75,95 \% \mathrm{Cl} 0.69-0.82$, sensitivity 78 , specificity $77, \mathrm{p}<0.001)$. Using this cut of value for preoperative $\mathrm{Hb}$, it was associated with four fold increase in blood transfusion rates, with prolonged hospital and intensive care stay.

\section{Discussion}

This retrospect study of patients undergoing major hepatobiliary surgery has revealed that preoperative anaemia is a potential reversible risk factor for blood transfusion and prolonged length of hospital and critical care stay. The potential cost savings by implementing a preoperative anaemia service as well as the reduction in the need for blood transfusion are massive and suggests that this needs to be explored further in this high risk group of patients. We believe this is the first time optimal $\mathrm{Hb}$ levels have been assessed to make the most cost effective treatment pathway. 